\title{
EDUCAÇÃO AMBIENTAL NO PARQUE ESTADUAL DO CANTÃO, TOCANTINS - UMA EXPERIÊNCIA NA TRANSIÇÃO ENTRE O CERRADO E A AMAZÔNIA ${ }^{1}$
}

\section{ENVIRONMENTAL EDUCATION AT THE STATE PARK OF THE CANTÃO, STATE OF TOCANTINS, BRAZIL - AN EXPERIENCE AT THE TRANSITION BETWEEN BRAZILIAN SAVANNA AND THE AMAZONIAN FOREST}

\author{
Carolina Joly MOREIRA ${ }^{2}$ \\ Marcileia Oliveira BISPO ${ }^{3}$
}

\begin{abstract}
Resumo: O presente artigo aborda o tema da Educação Ambiental em escolas do entorno de unidades de conservação, através de revisão bibliográfica sobre o tema e de um estudo de caso em uma escola pública de Ensino Fundamental, do município de Caseara no estado do Tocantins, vizinha ao Parque Estadual do Cantão, uma das áreas protegidas mais relevantes do bioma Amazônico. O estudo mostra a importância de reforçar o elo entre as áreas protegidas e suas respectivas comunidades de entorno, assegurando benefícios tanto para a gestão dessas áreas como para as próprias comunidades.
\end{abstract}

Palavras-Chaves: Educação Ambiental; Unidades de conservação; Parque Estadual do Cantão; Tocantins.

\begin{abstract}
This article discusses the topic of Environmental Education in surrounding schools of protected areas, through literature review on the subject and a case study in a public school in elementary school in the municipality of Caseara in Tocantins state of the Brazil, nearby the State Park of the Cantão, one of the most relevant protected areas of the Amazon biome. The study shows the importance of strengthening the link between protected areas and their surrounding communities, ensuring benefits both for the management of these areas and for the communities themselves.
\end{abstract}

Keywords: Environmental Education; Protected areas; State Park of the Cantão; Tocantins.

\section{Introdução}

O tema da Educação Ambiental em unidades de conservação é muitas vezes subjugado como uma tarefa secundária no hall de deveres e objetivos da gestão dessas áreas protegidas. Por terem muitas atribuições, os gestores, muitas vezes não dispõem de condições mínimas para cumprir o dever de educar os visitantes e muito menos a população do entorno das unidades. Assim, a parceria entre a gestão das unidades de conservação e as escolas das áreas de entorno são muito comuns e necessárias, do contrário, em muitos casos, nenhuma atividade de Educação Ambiental seria desenvolvida.

\footnotetext{
${ }^{1}$ Esta pesquisa foi desenvolvida através do Estagio Pós-doutoral realizado no Programa de Pós-graduação em Geografia -PPGG/UFT, campus de Porto Nacional, tendo como fonte de financiamento a Capes.

${ }^{2}$ Pós-doutora em Geografia e Doutoraem Ambiente e Sociedade. Endereço: carolina_joly@ hotmail.com

${ }^{3}$ Professora doutora na Graduação e Pós-graduação em geografia, Campus de Porto Nacional- UFT. E-mail: marcileia@uft.edu.br
} 
Para tal, é preciso que o professor responsável pelos conteúdos de Educação Ambiental esteja minimamente preparado e assistido para desenvolver as atividades relacionadas à presença e importância das áreas protegidas.

Neste artigo, tratamos de um estudo de caso em uma escola de Ensino Fundamental, do município de Caseara/TO, vizinha ao Parque Estadual do Cantão, uma das áreas protegidas mais relevantes do bioma Amazônico. O estudo é parte da pesquisa de pós-doutorado PNPD/CAPES, desenvolvida junto ao Programa de Pós-graduação em Geografia, da Universidade Federal do Tocantins.

O Parque Estadual do Cantão é composto por uma área de transição entre o Cerrado e a Floresta Amazônica, situado na extremidade norte da Ilha do Bananal, às margens do Rio Araguaia. Essas características conferem à unidade uma extraordinária riqueza de fauna e flora, além de abrigar centenas de lagos interiores, que se transformam em berçários para os peixes dessa região. A pesca é, portanto, uma atividade importante para os habitantes locais, tanto do ponto de vista comercial quanto cultural, como verificamos durante a atividade de Educação Ambiental desenvolvida junto aos alunos da escola José Alves de Assis, do município de Caseara/TO.

Essas características socioambientais reforçam a importância do desenvolvimento de pesquisas e trabalhos relacionados à Educação Ambiental, a serem tratados nas escolas do entorno de unidades de conservação, já que, ainda que se esteja carente de informações técnica sobre o assunto, essas unidades são, por outro lado, muito ricas em informação e experiência sobre a região. Essa pesquisa é um exemplo desta bonita troca.

\section{As políticas de Educação Ambiental}

Em uma perspectiva temporal, o tema e a legislação pertinentes à Educação Ambiental no Brasil se consolidaram em 1999, com a promulgação da Lei no 9.795 de 27 de abril de 1999, que institui a Política Nacional de Educação Ambiental (PNEA). Antes, portanto, da criação do Sistema Nacional de Unidades de Conservação (SNUC, 2000). Como afirmam Wick e Silva (2015),

Sem desconsiderarmos o processo de consolidação das UC e da EA, que se constituíram de forma independente, apontamos que em determinado momento elas se permearam. (...) A partir de então - e com a promulgação da Lei $\mathrm{n}^{\circ}$ 9.985, de 18 de julho de 2000, que cria e implementa o Sistema 
Nacional de Unidades de Conservação da Natureza (SNUC) - ficou instituído como objetivo das UCs promover a EA de forma a articulá-la aos seus programas de proteção. (WICK e SILVA, 2015)

O tema da Educação Ambiental em comunidades do entorno de unidades de conservação é abordado pela própria lei de criação do SNUC como uma contrapartida e uma obrigação do Estado no momento de criação de qualquer área protegida em território brasileiro. Os órgãos gestores das unidades, sejam eles federais, estaduais ou municipais, são obrigados a elaborar e concretizar ações de educação ambiental junto às comunidades do entorno, pois são diretamente atingidas pela criação dessas áreas.

Porém, segundo QUEIROZ (2013),

Ressalte-se que não é suficiente inserir a Educação Ambiental para cumprir a legislação ou simplesmente porque é "ecologicamente correto", é preciso ir além, articulando as ações a fim de transformar os espaços públicos de discussão em espaços de aprendizagem, de formação, espaços em que seja possível a construção de uma nova mentalidade individual e coletiva, ancorada no respeito mútuo, na democracia e na justiça socioambiental. Acrescentamos que a inserção da Educação Ambiental nas Unidades de Conservação deve não apenas direcionar para a sensibilização e interpretação ambiental - apesar destas serem consideradas de grande valor -, mas, trabalhar com o senso crítico da população, a fim de torná-la reflexiva, onde os sujeitos tenham capacidade de criar alternativas para a solução de problemas, tornando-se assim, mais participativos nos processos de tomada de decisão pelo poder público. (QUEIROZ, 2013:95)

Os órgãos federais então responsáveis pela execução da Política Nacional de Educação Ambiental (Lei federal N 9.795/1999), respectivamente o Ministério da Educação (MEC) e o Ministério do Meio Ambiente (MMA), até o final do ano de 2018, realizaram esforços para criar parâmetros, diretrizes e incentivos para que essa obrigação dos órgãos ambientais gestores das unidades de fato se concretizasse de maneira efetiva junto às comunidades.

A realização de oficinas, estudos e publicações elaboradas por esses órgãos buscavam atender essa demanda, como por exemplo a publicação da Série Educação Ambiental e Comunicação em Unidades de Conservação, composta por cinco volumes (MMA, 2015), publicados pelo Instituto Chico Mendes de Conservação da Biodiversidade (ICMBio), órgão responsável pelas unidades de conservação federais no país.

O aproveitamento de conceitos e práticas debatidos durante a elaboração do Programa Nacional de Educação Ambiental (PRONEA, 1996), que teve, em 2018, sua $5^{\text {a }}$ edição, também ocorreu. Este programa auxiliou a regulamentação da Política Nacional de 
Educação Ambiental (PNEA, 1999), e foi construído através de um amplo processo nacional de consulta pública, além de estar presente nessas ações de fomento à Educação Ambiental dos órgãos governamentais.

Após a sua elaboração, segundo Valentiet al, 2012,

O Instituto Brasileiro do Meio Ambiente e dos Recursos Naturais Renováveis - IBAMA - desenvolveu, de 1995 a 2006, diversas ações para a estruturação da Educação ambiental nas unidades de conservação, com enfoque principal na gestão participativa dessas áreas. (VALENTI et $a l, 2012: 270)$

De maneira mais específica, a proposta de intervenção pedagógica em escolas de comunidades que habitam o entorno de unidades de conservação é tratada em muitos estudos acadêmicos, de diferentes regiões do Brasil, considerando tanto os de proteção integral quanto as de uso sustentável.

Em um levantamento sobre estes estudos podemos destacar alguns como Valentiet al (2012), que, dentre outros objetivos, analisaram a influência do PRONEA nas práticas de Educação Ambiental desenvolvidas em cinquenta e seis unidades de conservação espalhadas pelo território brasileiro, sendo dezoito da região Norte, dezessete do Nordeste, duas do Centro-oeste, quinze do Sudeste e quatro da região Sul. Dessas unidades, quarenta e seis são administradas pelo governo federal, nove por governos estaduais e uma por governo municipal. Os dados foram obtidos através da aplicação de questionários junto aos gestores das unidades de conservação e suas respectivas equipes.

Segundo os próprios autores, o objetivo da pesquisa foi

(...) desenvolver um estudo exploratório sobre a educação ambiental realizada em unidades de conservação brasileiras em relação a públicos atendidos, parcerias, linhas pedagógicas adotadas, objetivos propostos, atividades realizadas, temas abordados, avaliação e documentos utilizados como referência. Além disso, analisamos uma possível influência do PRONEA nas práticas realizadas pelas unidades. (VALENTI et al, 2012:271)

Como resultado, avaliaram que o PRONEA de fato trouxe avanços para a Educação Ambiental praticada no país, mas é pouco difundido nas atividades relacionadas ao tema realizadas nas unidades de conservação, pois apenas $29 \%$ delas afirmou utilizar seus princípios como base. Outro dado relevante da pesquisa é que o público atendido pela maioria das unidades de conservação, nas atividades de educação ambiental, não se restringe ao público infantil, atingindo também públicos adultos das comunidades, como lideranças, 
organizações comunitárias, sindicatos e associações. Para os autores, esse dado revela uma evolução no entendimento da Educação Ambiental por parte das unidades de conservação, fruto da influência do PRONEA, pois passam a enxergá-la também como uma ferramenta na resolução de conflitos, inerente a toda unidade de conservação, realçando a perspectiva da Educação Ambiental crítica. Os autores também apuraram que um dos principais parceiros das atividades de Educação Ambiental nas unidades são as instituições de ensino, além de organizações não governamentais (ONGs) e instituições governamentais.

Outra conclusão dos autores é que há desarticulação entre os objetivos apontados pelas unidades de conservação e as atividades educacionais que exercem. As atividades mais recorrentes são as realizadas nas escolas, e, no entanto, inserir a Educação Ambiental como um tema transversal nas escolas aparece em décimo lugar na lista de principais objetivos dos educadores das unidades de conservação entrevistadas.

O fato de as atividades de Educação Ambiental serem ações mais recorrentes no ambiente escolar surpreendeu os autores, que justificaram, afirmando que o ambiente escolar oferece oportunidade de se trabalhar com ações mais continuadas e menos pontuais, e apesar de as unidades de conservação não serem responsáveis pela inserção da educação ambiental no currículo escolar, elas possuem um ambiente de ensino que propicia o contato direto com temas tratados em sala de aula.

Entretanto, o fato da real dificuldade que a maioria das escolas enfrentam para transportar os alunos em visita às unidades de conservação não foi apontada pelos autores. Além disso, para que as visitas se realizem, além do transporte, é necessária uma infraestrutura mínima de recepção e acomodação aos alunos, como um centro de visitantes, por exemplo. Porém, poucas são as unidades de conservação que possuem tal característica. $\mathrm{O}$ Parque Estadual do Cantão, neste quesito, é uma exceção, pois possui um centro de visitantes bem equipado, que, dentre outras dependências, possui um auditório para acomodação de 80 pessoas.

Outro estudo elaborado sobre a qualidade da Educação Ambiental voltada ao público escolar, realizada por unidades de conservação, fez uma comparação com as práticas de Educação Ambiental desenvolvidas em áreas protegidas de Portugal. Oliveira et al (2014) concluíram que:

O Brasil possui vários documentos orientadores sobre Educação Ambiental, bem como Políticas Públicas e legislações específicas sobre o tema. Em todos esses documentos, a promoção da Educação ambiental é indicada em todos os âmbitos, tanto no ensino formal, quanto não formal. Entretanto 
constata-se que nas escolas inseridas nas UC, seja ao professor, seja aos alunos, não existe um programa para a (in)formação específica, nem tem suporte para realizar ações de EA na escola. De fato, os órgãos gestores estaduais ou municipais não estabelecem tais tipos de programas com a população diretamente afetada pela implantação da UC. (OLIVEIRA et al, 2014:13)

Na realidade, a elaboração do PRONEA foi justamente para tentar sanar essa lacuna na formação de educadores ambientais, mas daqueles que trabalham nas unidades de conservação e não de professores das redes de ensino. $\mathrm{O}$ curso oferecido pelo IBAMA que utiliza princípios do PRONEA mencionado por Valenti et al (2012) teve como público alvo justamente esses profissionais das unidades de conservação, sobretudo da esfera federal de áreas protegidas. Os funcionários de unidades de conservação estaduais e municipais tiveram menor participação nessa atividade de capacitação oferecida pelo IBAMA.

As temáticas muito focadas no uso de recursos e na limitação de atividades que as unidades de conservação necessariamente trazem, também são apontadas por Oliveira et al (2014) como um fator desmotivador na Educação Ambiental trabalhada em muitas unidades brasileiras. Assim, perde-se a oportunidade de tratar de temas relacionados a elementos culturais, históricos e socioeconômicos da região. Ou, ainda mais grave, essa atitude reforça o distanciamento entre a população e, por conseguinte, os alunos, e as unidades de conservação, constituindo um movimento, na realidade, contrário à Educação Ambiental, segundo os autores.

No entanto, os educadores ambientais que absorveram os princípios e práticas do PRONEA possuem uma visão diferenciada sobre as principais questões ambientais envolvendo as áreas protegidas, tendendo à vertente da chamada Educação Ambiental crítica, que trata de temas como "participação na criação e gestão da UC", "conservação do meio ambiente", difundir a "legislação ambiental", "valorizar a cultura e saberes tradicionais", "contribuir para a construção de sociedades sustentáveis", entre outros. (VALENTI et al, 2012)

Para Queiroz e Guimarães (2016), que também defendem a vertente da Educação Ambiental crítica e emancipatória,

(...) a inserção da Educação Ambiental nas unidades de conservação deve, não apenas direcionar para a sensibilização e interpretação ambiental - apesar destas serem consideradas de grande valor -, mas, trabalhar com senso crítico da população, a fim de torná-la reflexiva e sensível, onde os sujeitos tenham capacidade de criar alternativas para o enfrentamento dos problemas socioambientais, tornando-se assim, mais participativos nos processos de tomada de decisão junto ao poder público, por meio de novas práticas 
reflexivas. Ou seja, tendo uma nova práxis de intervenção na realidade, como resultado do processo formativo. (QUEIROZ e GUIMARÃES, 2016:424).

Contudo, a conclusão de Valenti et al (2012) e de Oliveira et al (2014) é semelhante, pois de uma forma ou de outra, afirmam que a capacidade de tratar de temas relacionados à Educação Ambiental não tem o alcance necessário para que o educador realmente provoque mudanças na relação entre as comunidades afetadas por unidades de conservação e as áreas protegidas. Para Oliveira et al (2014), o tema deveria necessariamente ser abordado nas salas de aula de comunidades afetadas, de preferência com o enfoque em elementos socioambientais. E para Valenti et al (2012), as políticas públicas de larga escala, como o PRONEA, foram importantes para trazer as mudanças desejadas na área da Educação Ambiental nas unidades de conservação, mas essas mudanças não conseguiram atingir as práticas educativas. Para eles é preciso haver formação continuada dos educadores ambientais que atuam em unidades de conservação de todo o país. Ou seja, as transformações preconizadas por esse grande programa de Educação Ambiental, que já se encontra em sua quinta edição, ainda não conseguiram atingir o grande agente de transformação do processo, que é o educador ambiental, o professor.

Mesmo assim, o tema Educação Ambiental e todo o aparato legal e institucional construído durante mais de vinte anos na esfera do governo federal, foram desarticulados e descontinuados, pelo menos até o presente momento, com a nova gestão que assumiu o Poder Executivo no ano de 2019. A prerrogativa de abrigar todo o arcabouço de planejamento e execução das políticas públicas do tema Educação Ambiental não está mais centrada no Ministério do Meio Ambiente e ainda aguarda um redirecionamento.

\section{O Parque Estadual do Cantão}

O Parque Estadual do Cantão foi a primeira unidade de conservação de proteção integral, criada no Tocantins no dia 14 de julho de 1998, por meio da Lei Estadual $N^{\circ} 996$, e é considerada uma das áreas protegidas mais importantes da Amazônia brasileira, devido a sua grande diversidade biológica (Figura 1). A unidade abriga área de três municípios tocantinenses: Caseara, Marianópolis do Tocantins e Pium (Figura 2). 
Figura 1 - Mapa De Localização Do Parque Estadual Do Cantão.

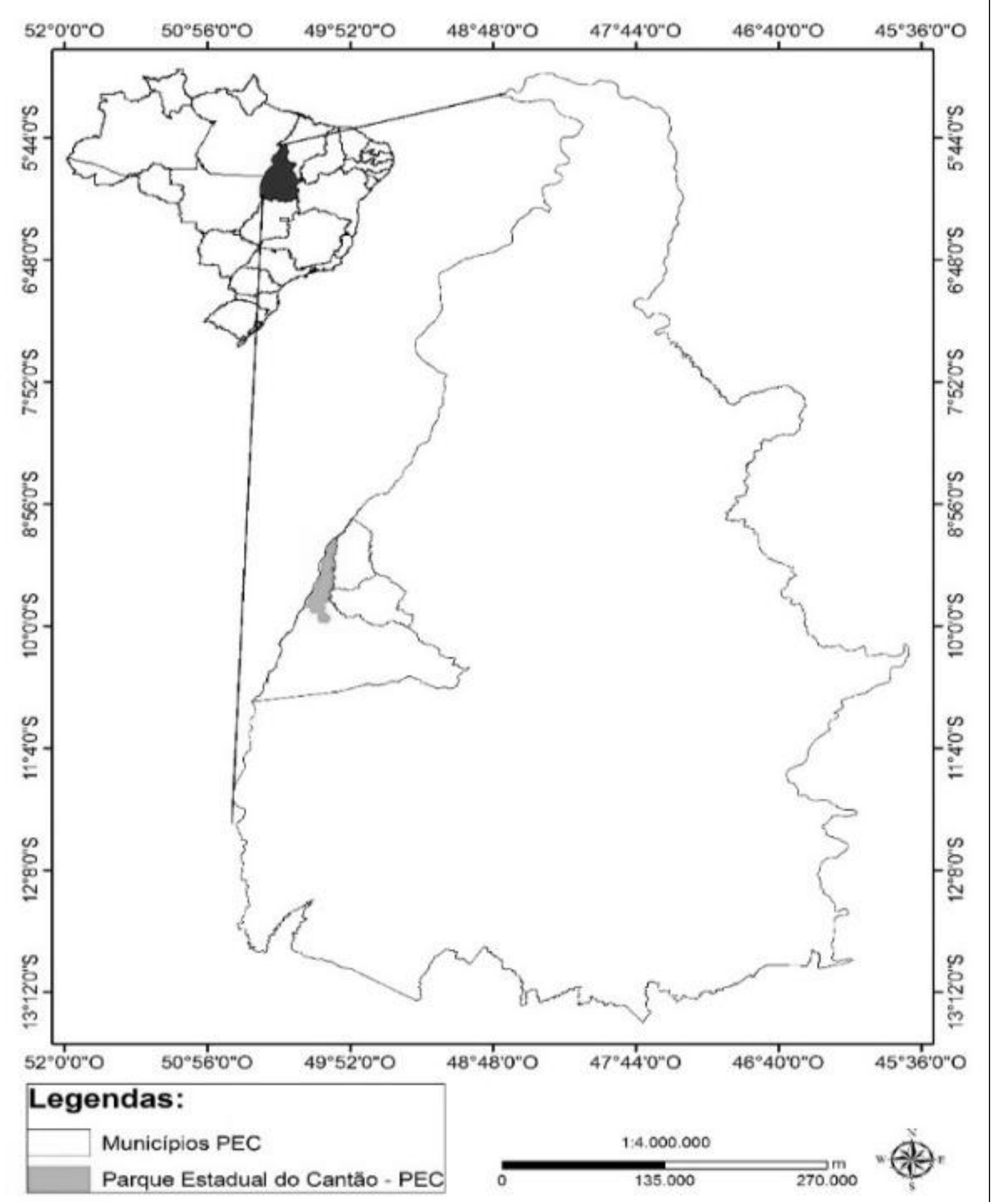

Fonte: MOREIRA, C. J. (2019). 
Figura 2- Municípios Abrangidos Pelo Parque Estadual Do Cantão.

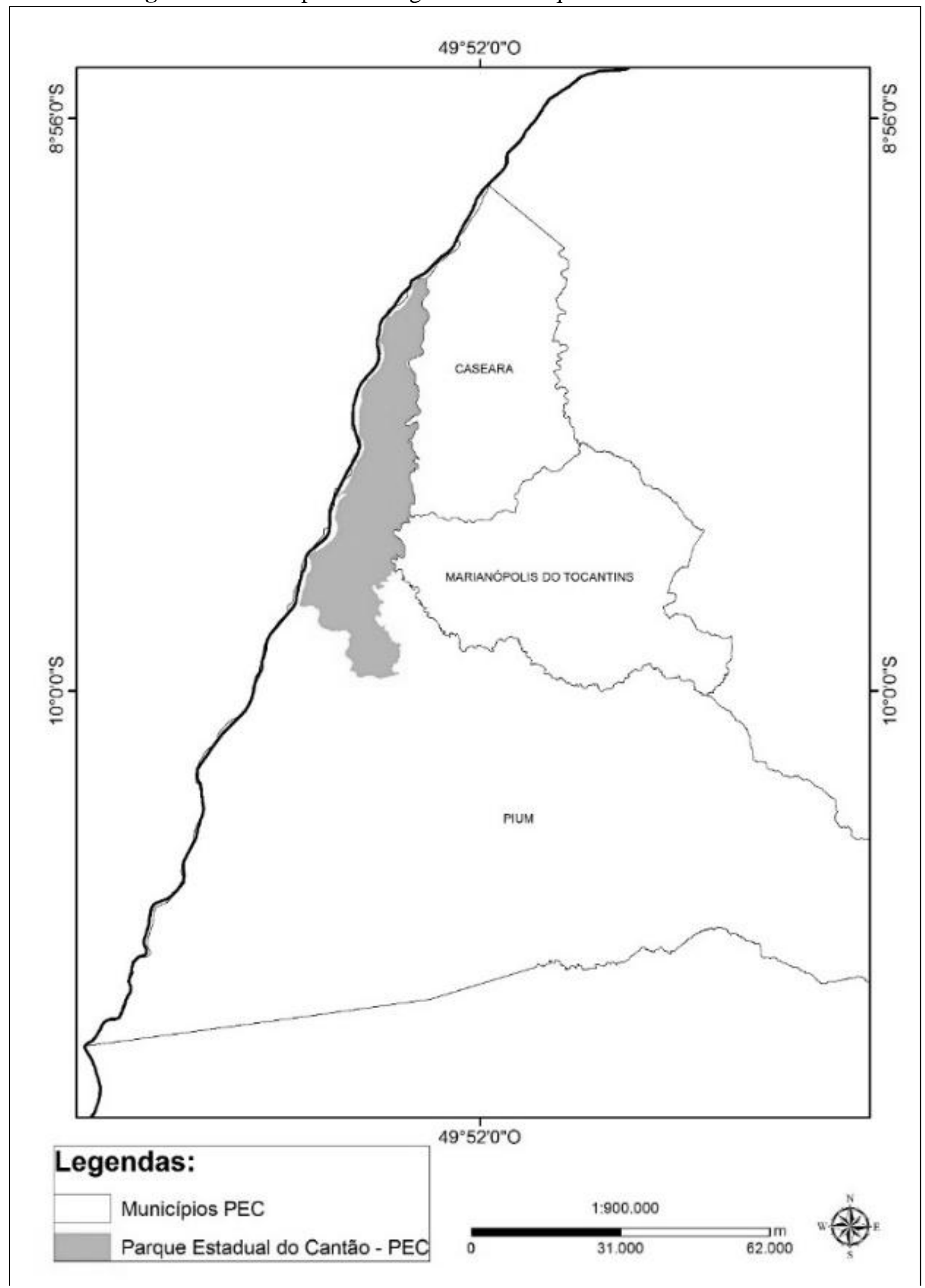

Fonte: MOREIRA, C. J. (2019). 
Esta unidade de conservação de quase 90 mil hectares, protege significativas populações de ariranhas, onças-pintadas, jacarés-açu, harpias, entre outros animais, inclusive alguns ameaçados de extinção. O parque abriga biomas com características singulares e especiais, pois é uma área de transição entre Cerrado e florestas de igapó, típicas do bioma amazônico (NATURATINS, 2017). Contígua ao Parque Nacional do Araguaia, a unidade abriga mais de oitocentos lagos internos, que, na época de cheia, transbordam e se reconectam, repovoando o Rio Araguaia com alevinos de espécies variadas e, inclusive, ameaçadas, como o pirarucu.

O Parque Estadual do Cantão é a única unidade de conservação do estado do Tocantins que recebe recursos federais, previstos através do Programa Áreas Protegidas da Amazônia (ARPA), justamente por proteger importantes remanescentes de Floresta Amazônica em sua área. O programa, que foi criado em 2002, é coordenado pelo Ministério do Meio Ambiente (MMA), mantido por recursos do Banco Mundial e administrado através de uma associação civil sem fins lucrativos, o Fundo Brasileiro para Biodiversidade (FUNBIO).

\section{Metodologia da pesquisa}

A primeira parte da pesquisa consistiu na elaboração de revisão bibliográfica sobre o tema Educação Ambiental em Unidades de Conservação, através de busca digital de publicações e legislação pertinente.

O segundo momento da pesquisa consistiu na proposta de intervenção pedagógica de Educação Ambiental em instituição de ensino localizada no entorno de unidade de conservação no Tocantins. A unidade escolhida foi o Parque Estadual do Cantão, área protegida de proteção integral mais antiga do Estado, localizada na extremidade norte da Ilha do Bananal, às margens do Rio Araguaia.

A escola participante da atividade foi a Escola Estadual José Alves de Assis, que abriga turmas de Ensino Fundamental II, localizada na área urbana do município de Caseara/TO. As propostas de intervenção pedagógica foram apresentadas à coordenação e aos professores de Geografia e de Ciências da escola, que sugeriram algumas adequações e a quais turmas cada atividade poderia ser aplicada. 
Participaram da atividade as turmas de sexto, sétimo e oitavo ano do período matutino, totalizando sessenta quatro alunos. Cada turma realizou uma proposta de atividade diferente, envolvendo desenhos, elaboração de história e interpretação cartográfica da região. O fato de os alunos dessas turmas conhecerem previamente o Parque Estadual do Cantão foi essencial para a realização das atividades.

O roteiro das atividades propostas segue abaixo:

Atividade $1\left(6^{\circ}\right.$ ano $)$

1) Em qual cidade você mora? Você nasceu nessa cidade?

2) Quando você vai para a escola o que costuma ver pelo caminho? Faça um desenho desse caminho.

3) Você passa por algum rio ou lago? Você sabe o nome dele? Faça um desenho desse rio ou lago.

4) Você já pescou em algum rio ou lago da sua região?

5) Quem te levou para pescar? Que peixes você já pescou? Faça um desenho do seu peixe preferido.

6) Você costuma ir à praia?

7) Que animais você costuma ver perto da sua casa? Tem algum que você goste ou ache bonito? Faça um desenho dele.Qual animal você não gosta ou tem medo? Por quê? Faça um desenho dele também.

8) E nomes de árvores, você conhece algum? Tem alguma árvore que ache mais bonita? Tem alguma que serve de remédio? E de tempero? A madeira delas é boa para fazer o quê? Faça um desenho da árvore que mais gosta.

9) Você já visitou o Parque do Cantão? O que achou de lá? Faça um desenho do que mais gostou no parque.

10) O que você mais gosta no lugar onde você vive? E o que menos gosta?

Atividade $2\left(7^{\circ}\right.$ ano $)$

Leia a história a seguir e complete o final, use sua imaginação! 
Certa noite de lua, como tantas outras, quando a filharada se reunia no terreiro para ouvir seu Braz contar suas estórias ao pé da fogueira, comendo milho verde colhido da roça, chega um vizinho, morador da Lagoinha, muito aflito e esbravejando: - Saiam todos daqui! Vão já pra dentro de casa! E os home que peguem suas garrucha! Tem um monstro à solta no caminho e vem vindo pra cá! É o lobisomem sim senhor, que vem vindo! Vamo homarada, se armá e esperá a fera!

Seo Braz passou a mão na criançada e botou todo mundo pra dentro de casa, que ficou no escuro completo, pois era melhor não ascender as lamparinas. Os homens apagaram a fogueira, pegaram suas carabinas e se esconderam pelo mato, esperando o tal lobisomem. Ninguém ali nunca tinha visto um, nem sabiam como ele era, mas, pelo sim pelo não... E agora? Será que era mesmo o lobisomem? Alguns se perguntavam.

De repente, na direção da mata, lá vinha a fera, peluda e de andar muito lento, só se via sua silhueta, conforme a luz da lua! Um cheiro forte de bicho se espalhou pelo redor. Será que a fera os espreitava com seu faro de lobo? O medo na espinha correu por todos ali, na criançada nem se fala! Foi então que Seo João da Cruz não se aguentou de nervoso e deu um berro saindo do mato onde se escondia: - Sai, cruz credo!! Valei-me Nossa Senhora! Me livra dessa fera dos inferno!! - e correu pela estrada de chão até sumir na escuridão do caminho.

E pra espanto de todos que ainda se encolhiam em suas tocas e tocaias, o lobisomem ficou ali parado, sem reação. Que fera mais pacífica, pensou Seo Braz, será que tá de barriga cheia? Passou mais algum tempo, e a fera ali, sem fazer nada. Seo Braz chamou seu compadre Manoel de lado e cochichou: - Vamo ascende uma tocha com querosene, pra gente vê o que a fera tá fazendo. Se ela num gostá, a gente joga a tocha na besta mermo e que Deus nos ajude!

Quando os dois ascenderam a tocha e o clarão iluminou o terreiro, foi uma gargalhada só! O alívio inundou as almas adultas e a curiosidade a das crianças ali presentes! Que lobisomem que nada, era um baita tamanduá!!

\footnotetext{
${ }^{4}$ Trecho de texto elaborado por Carolina Joly Moreira.
} 
EM

QUESTÃO

Atividade 3 ( $8^{\circ}$ ano)

O mapa da Figura 3 mostra em cinza o Parque Estadual do Cantão, que é delimitado por três rios diferentes. Complete no mapa o nome de cada um desses rios mostrando onde se localizam.

Figura 3 - Mapa De Localização Dos Rios Que Delimitam O Parque Estadual Do Cantão.

\section{Parque Estadual do Cantão}

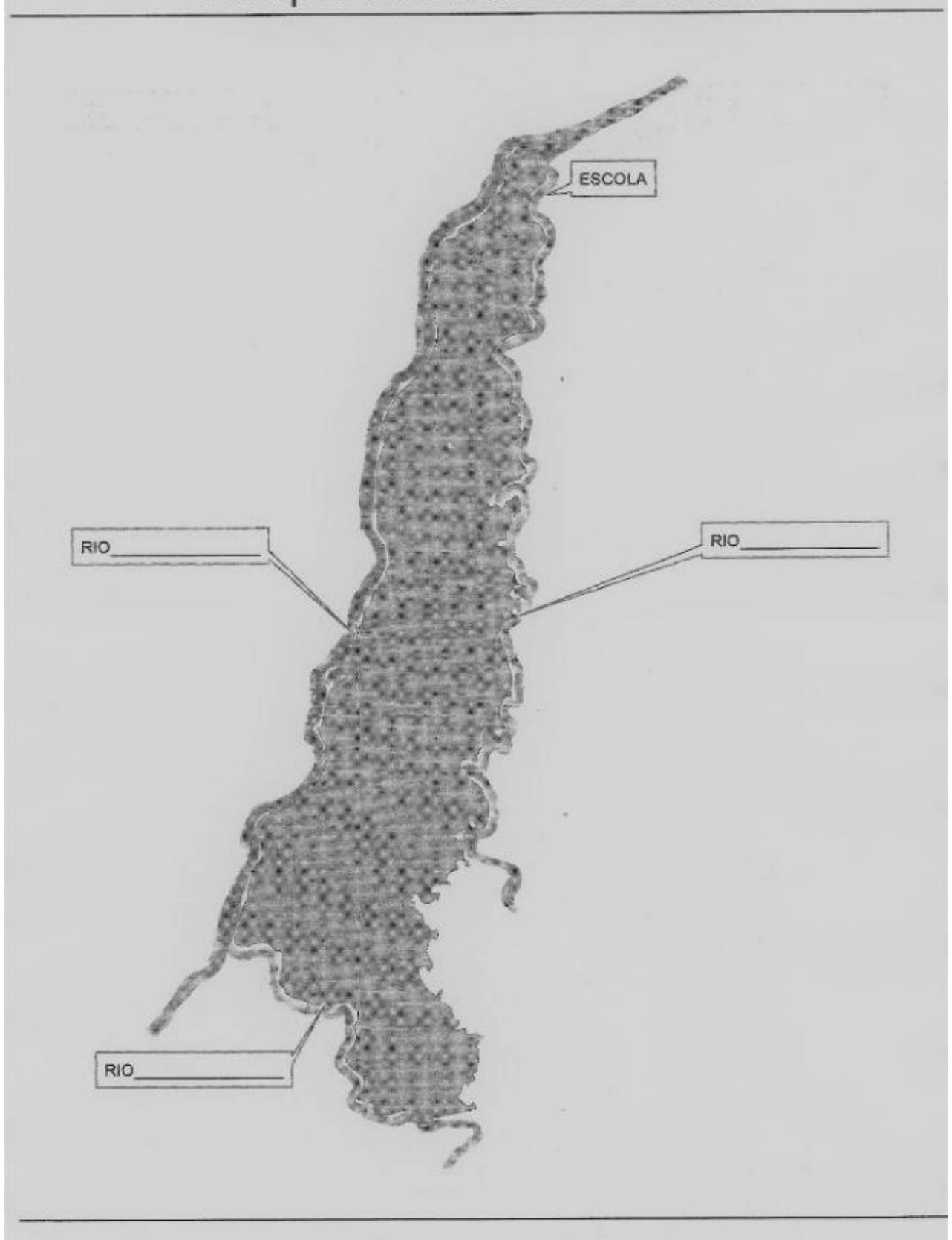

Fonte: MOREIRA, C. J. (2019). 


\section{Resultados e discussão}

Após a aplicação das atividades, as respostas foram analisadas e os desenhos foram digitalizados. A análise mostrou que os alunos, de maneira geral, demonstraram bom conhecimento sobre os peixes da região, mas desconhecem ou não têm contato com outros animais silvestres, embora esses sejam abundantes na paisagem da cidade: observa-se a presença de araras, tucanos, botos, entre outros. Os alunos demonstraram mais contato e conhecimento sobre animais domésticos. Entretanto, temem cobras e aranhas, que também são abundantes, mesmo na área urbana da cidade.

A prática da pesca é muito comum e valorizada entre eles, que são levados, pelos pais ou avós, a aprender desde cedo, transformando a atividade em um hábito cultural, embora seja proibida nas dependências do Parque. Muitos escolheram os lagos e o rio como os elementos que mais gostaram na visita que fizeram à unidade, mostrando uma relação positiva com estes recursos.

A maioria das famílias veio de outra cidade e mora na área urbana de Caseara, pois é um município com maior infraestrutura e comércio.

$\mathrm{Na}$ atividade de redação, observamos alguns indícios da prática da caça de animais silvestres, atividade também proibida, mas ainda assim presente nos hábitos culturais da região. No entanto, também identificamos elementos de apego e respeito aos animais silvestres da região, registrados na publicação derivada destas atividades realizadas na escola ${ }^{5}$.

Contudo, a atividade de identificação dos rios utilizando material cartográfico foi a que mais nos surpreendeu, pois a maioria dos alunos não soube identificar corretamente os rios que banham a região e que delimitam o Parque Estadual do Cantão, embora seja um hábito frequente, entre eles, a navegação na área, motivada pela pesca. Os alunos deveriam identificar e nomear três rios: Araguaia (a oeste), do Coco (a leste) e Javaés (ao sul). (Figura 3)

A maioria dos estudantes inverteu as posições dos Rios Araguaia e do Coco, embora o curso deste último passe a poucos metros da escola, evidenciando uma possível dificuldade com a interpretação cartográfica por parte dos alunos. Além disso, todos eles nomearam o Rio Javaés como Rio Caiapó, que fica, na realidade, em outra sub-bacia hidrográfica, próxima à região (SEPLAN, 2012).

\footnotetext{
${ }^{5}$ (En)Cantão - Educação Ambiental e sociobiodiversidade no entorno do Parque Estadual do Cantão (TO), Artesam, Porto Nacional, 2019.
} 
As produções de desenhos e histórias dos alunos elaborados durante essa intervenção pedagógica, resultaram em uma publicação didática sobre o Parque Estadual do Cantão e a sociobiodiversidade da região, intitulada: (En)Cantão - Educação Ambiental e sociobiodiversidade no entorno do Parque Estadual do Cantão (TO), disponível em https:// Www.flipsnack.com/naturatins/livreto-encant-o-digital.html

As cópias de tal publicação foram encaminhadas à Escola Estadual José Alves de Assis, com a finalidade de subsidiar futuras atividades de Geografia e Educação Ambiental relacionadas ao Parque.

\section{Considerações Finais}

A região do Cantão é marcada pela presença de unidades de conservação há muitas décadas, iniciadas com a criação do Parque Nacional do Araguaia, em 1959. Atualmente, existe um mosaico de unidades de conservação na região, tanto de proteção integral quanto de desenvolvimento sustentável, além das terras indígenas, também consideradas como áreas ambientalmente protegidas. (Figura 4)

No entanto, ainda há, de maneira geral, carência de compreensão sobre o papel dessas unidades junto à comunidade local, até mesmo sobre a existência delas (MOREIRA, 2016). Por essa razão a Educação Ambiental é tão importante, sobretudo nas escolas da região.

De acordo com Becker (2009), novos componentes ampliam o desafio de compreender e gerir as unidades de conservação. A autora afirma que:

Um questionamento sobre sua finalidade origina-se nas próprias populações por elas afetadas em suas legítimas demandas de melhoria de condições de vida, uma vez que a mera preservação não gera riqueza, trabalho, renda, habitação e serviços necessários para alcançar as melhorias desejadas. (BECKER, 2009:18)

E, muitas vezes, a preservação em si pode até contribuir negativamente para a vida de populações que são expropriadas do seu direito à terra, pois não são devidamente indenizadas no momento da criação de unidades de proteção integral, sobretudo quando não possuem o título da terra, como é justamente o caso do Parque Estadual do Cantão e de muitas outras unidades espalhadas pelo território brasileiro. 
Figura 4 - Mapa do Mosaico de Unidades de Conservação localizadas na região do Cantão.
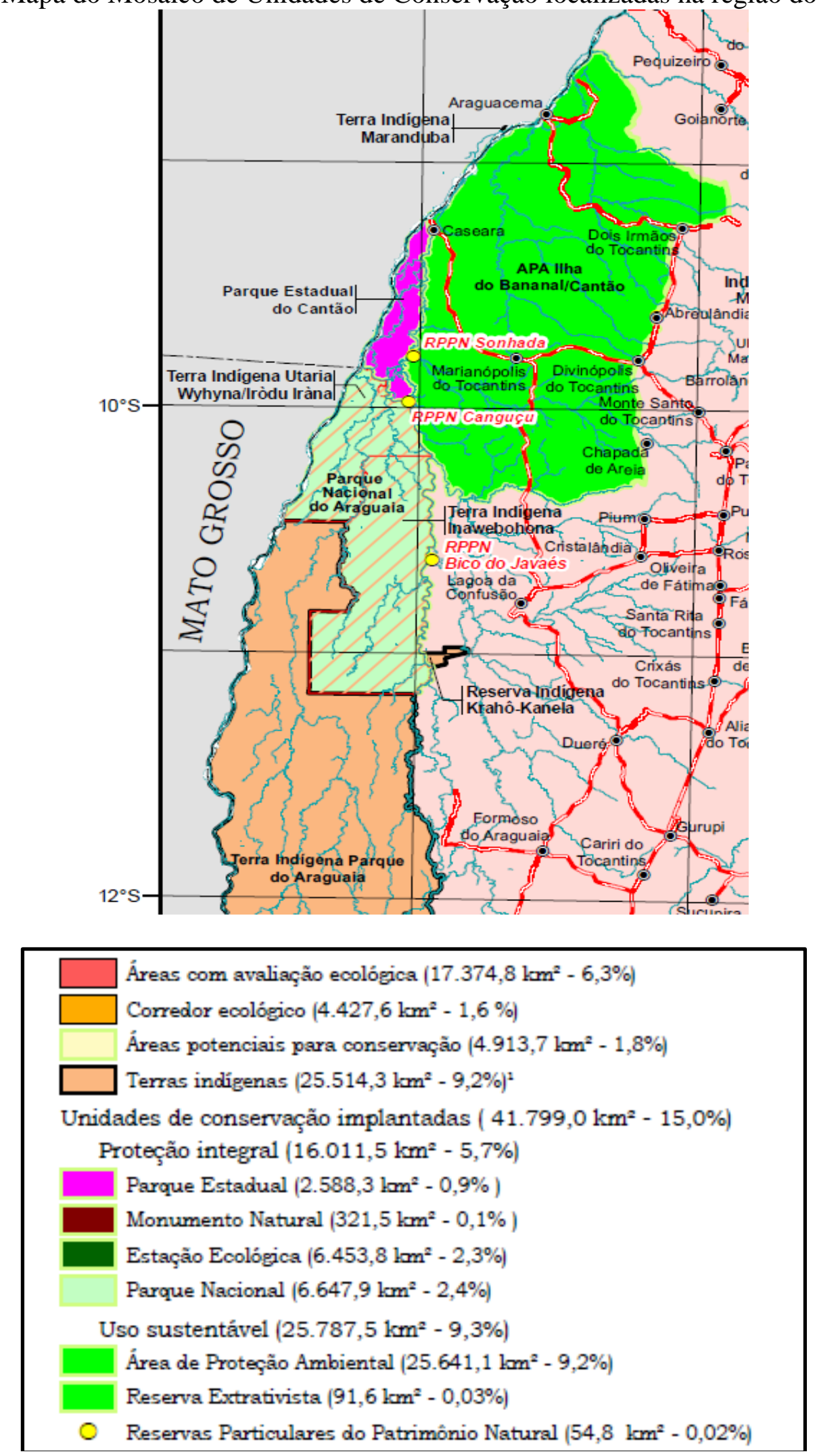

Fonte: SEPLAN (2012). 
Antes da criação do Parque, a área era habitada por algumas famílias de ribeirinhos, que não possuíam o título de posse da terra. Ocupavam porções de terras mais altas, que no inverno (época das cheias dos rios) não ficavam alagadas, denominadas popularmente de “torrões”. Daí a expressão local "torrãozeiro" para designar os membros dessas famílias, que até hoje aguardam indenização do poder público por terem sido expropriados de suas terras. Hoje, vivem em Caseara e se organizaram em uma associação, a fim de continuar reivindicando seus direitos.

Essa conduta do poder público só contribui para a visão negativa das áreas protegidas junto à sociedade. É urgente uma mudança de postura do Estado com relação a esse aspecto.

A Educação Ambiental, sobretudo em sua vertente crítica, é, nesse caso, a principal ferramenta de informação, emancipação e participação que os habitantes da região necessitam. Para Queiroz (2013), o ordenamento territorial, criado, no caso das unidades de conservação, para garantir a preservação do patrimônio natural e cultural, encontra na Educação Ambiental

(...) subsídios para a efetivação de práticas sustentáveis que fortaleçam políticas de ordenamento territorial e ambiental. Assim, a Educação Ambiental tem a pretensão de contribuir para o amadurecimento, crescimento e fortalecimento do saber, da ação, da reflexão e na construção de um caminho de transformação social, uma vez que é parte do processo de compreensão da realidade. (QUEIROZ, 2013:94)

Contudo, esse quadro de desinformação e questionamento sobre a existência e relevância das unidades de conservação não são um fenômeno restrito à região do Cantão. Pelo contrário, são muito comuns em todas as regiões do país, pois a criação dessas áreas necessariamente gera conflitos de interesse. Essa discussão nos remete, então, a uma visão mais ampla sobre as políticas públicas de Educação Ambiental no Brasil construída e praticada nas últimas décadas. Apesar dos esforços e grandes programas federais de impulsionamento das práticas de Educação Ambiental no país, o educador (o professor) ainda não conseguiu exercer seu papel transformador, como apontado anteriormente.

A necessidade de intensificar as práticas e a abordagem crítica da Educação Ambiental em comunidades escolares do entorno de unidades de conservação, como as de Caseara, por exemplo, é real e urgente, pois os alunos têm o potencial de envolvimento e compreensão da relevância dessas áreas, bastando trabalhar o conteúdo diretamente relacionados à presença do Parque. Os professores devem ser mais incentivados e mesmo 
despertados para a necessidade dessa temática, independente do trabalho realizado pela equipe do Parque.

Os alunos gostam de mostrar que conhecem a região, valorizar esse conhecimento sobre os peixes, sobre os rios e seus mistérios, as práticas de pesca, as épocas de cada coisa, é valorizar a cultura ribeirinha, entendê-la como parte do Cantão e caminho para a valorização da área protegida também. As escolas da região não devem perder a oportunidade de fazer parte deste processo.

A Educação Ambiental tem a difícil missão de evitar um quadro futuro no qual o Brasil, de país exemplo em conservação, passe à nação do medo do próximo desastre ambiental. E na linha de frente desta batalha está o professor, munido apenas de parco conhecimento sobre os complexos assuntos relacionados a como se deveria estabelecer nossa relação com o mundo em que vivemos, para que possamos viver melhor.

É urgente, portanto, a retomada dos programas governamentais voltados à Educação Ambiental, além de elaborar formas de fazer as discussões e conteúdos chegarem ao professor, ao educador ambiental, que, por sua vez, deve desenvolver a capacidade de fazer adaptações à sua realidade, aos problemas vivenciados por sua comunidade.

Também é imperativo que a nossa sociedade compreenda e valorize a responsabilidade e o privilégio que ainda temos de zelar por um patrimônio ambiental e cultural que muitas nações gostariam de ter em seu território. E o único caminho para alcançar esse objetivo é através da educação, em seu sentido mais amplo e, acima de tudo, crítico.

\section{Referências}

BECKER, Bertha Koiffmann. Novas territorialidades na Amazônia: desafio às políticas públicas. Boletim do Museu Paraense Emílio Goeldi. Ciências Humanas. Belém, vol.5, n¹, pp.17-23. Jan-Abr, 2010.

BRASIL. Política Nacional de Educação Ambiental (PNEA). Lei federal Nº.795 de 27 de abril de 1999.

. Programa Nacional de Educação Ambiental (PRONEA). Ministério do Meio Ambiente, Brasília, 1996.

. Sistema Nacional de Unidades de Conservação (SNUC). Lei federal N9.985 de 18 de julho de 2000. 
LOUREIRO, Carlos Frederico Bernardo. Complexidade e dialética: contribuições à práxis política e emancipatória em educação ambiental. Educação e Sociedade. Campinas v. 26, n.93, p.1473-1494. set/dez. 2005.

MOREIRA, Carolina Joly. (En)Cantão - Educação ambiental e socio biodiversidade no entorno do Parque Estadual do Cantão (TO). Artesam, Porto Nacional, 16 p., 2019. Livro ebook. Disponível em http://repositorio.uft.edu.br/bitstream/11612/2223/1/Carolina\%20Joly\%20Moreira\%20\%20Relat\%C3\%B3rio\%20de\%20P\%C3\%B3s\%20Doc.pdf

; BISPO, Marciléia Oliveira. Políticas públicas em Educação Ambiental no Brasil alguns fatores de desconstrução. Revista Terceiro Incluído. Universidade Federal de Goiás (UFG). Goiânia, vol. 08, pp.49-61, 2018.

MOREIRA, Deny Cesar. Análise da expansão da cultura da soja na APA Ilha do Bananal/Cantão - Tocantins. Dissertação de mestrado. Universidade Federal do Tocantins (UFT). Palmas, 2016.

OLIVEIRA, Cauê N.; IMBERNON, Rosely, A. L.; GONÇALVES, Pedro W.; BRILHA, José Bernardo R. Contribuições para o desenvolvimento da Educação Ambiental em Unidades de Conservação no Brasil a partir de programas educativos do Geoparque Naturtejo (Portugal). Terrae, $n^{\circ} 11$, pp.03-14, Campinas, 2014.

QUEIROZ, Edileuza Dias. Contribuições da Educação Ambiental Crítica para o uso público sustentável em unidades de conservação. Anais - Uso público em unidades de conservação, vol.01, $\mathrm{n}^{\circ} 01$, Universidade Federal Fluminense (UFF). Niterói, 2013.

; GUIMARÃES, Mauro. O trabalho de campo em unidades de conservação como ambiente educativo e estratégia pedagógica fundamental para uma formação diferenciada em educação ambiental. Revista de Políticas Públicas. Universidade Federal do Maranhão (UFMA), Número especial, pp.421-425, São Luís, 2016.

TOCANTINS. Secretaria da Fazenda e de Planejamento (SEPLAN). Áreas de uso legal restrito e potenciais à conservação ambiental. Palmas, 2012.

VALENTI, Mayla Wilik; OLIVEIRA, Haydée Torres; DODONOV, Pavel; SILVA, Maura Machado. Educação Ambiental em unidades de conservação: políticas públicas e a prática educativa. Educação em Revista, vol.28, n01, pp.267-288. Belo Horizonte, 2012.

WICK, Maíra Arantes Leite; SILVA, Luciano Fernandes. Unidades de conservação e processos de educação ambiental. Revista Brasileira de Educação Ambiental, vol. 10, $\mathrm{n}^{\circ}$ 01, pp.201-220. São Paulo, 2015. 